\title{
Lentinula edodes Mycelium as Effective Agent for Piroxicam Mycoremediation
}

\author{
Bożena Muszyńska ${ }^{1}$, Monika Dąbrowska ${ }^{2 *}$, Małgorzata Starek², Paweł Żmudzkiª, \\ Jan Lazur ${ }^{1}$, Jolanta Pytko-Polończyk ${ }^{4}$ and Włodzimierz Opoka ${ }^{2}$ \\ ${ }^{1}$ Department of Pharmaceutical Botany, Faculty of Pharmacy, Jagiellonian University Medical College, Kraków, Poland, \\ ${ }^{2}$ Department of Inorganic Chemistry, Faculty of Pharmacy, Jagiellonian University Medical College, Kraków, Poland, \\ ${ }^{3}$ Department of Medicinal Chemistry, Faculty of Pharmacy, Jagiellonian University Medical College, Kraków, Poland, \\ ${ }^{4}$ Department of Integrated Dentistry, Jagiellonian University Medical College, Kraków, Poland
}

Pollution of the environment with inorganic and organic substances is one of the main problems in the world. For this reason, it is necessary to conduct researches for effective methods of biodegradation of xenobiotics, including drugs whose unmetabolized forms are introduced into the environment, especially into water. One possible solution to this problem may be the use of white rot fungi, such as Lentinula edodes. This is an edible species used in medicine because of its beneficial anti-cancer, hypocholesterolemic, hypotensive, hypoglycemic and antioxidant effects. Due to the fact that the mycelium of $L$. edodes produces enzymes with oxidizing properties that can degrade xenobiotics. The aim of the work was verification if in vitro cultures of $L$. edodes can be used for bioremediation of non-steroidal, anti-inflammatory drug: piroxicam. For this purpose, the in vitro culture of $L$. edodes was derived and the mycelial cultures of this species enriched with piroxicam were analyzed. The biodegradation pathway of piroxicam by L. edodes mycelium was carried out by the UPLC/MS/MS method. The degradation process of piroxicam was found to affect primarily the linker between the thiazine and the piperidine ring, leading to its oxidation and cleavage. Additionally, oxidation of the benzothiazine moiety was observed, leading to hydroxylation and oxidation of the phenyl ring as well as oxidation of the thiazine ring leading to partial or complete removal of the sulfonamide moiety. It seems that the degradation process led finally to 2-hydroxybenozquinone, which may be further oxidized to inorganic compounds. What's more, concentration of piroxicam in in vitro cultures of $L$. edodes was not correlated with effectiveness of biodegradation of this compound - on each experimental series, the level of degradation was the same. The results confirm the possibility of using the investigated $L$. edodes mycelium for remediation of piroxicam.

Keywords: bioremediation, edible mushroom, Lentinula edodes, piroxicam, UPLC/MS/MS analysis

\section{INTRODUCTION}

Pollution of the environment with inorganic and organic substances has become one of the main problems in the world. The main goal is to look for an effective method of biodegradation of xenobiotics, including drugs whose excess or unmetabolized forms are introduced into the environment (Das, 2005; Kulshreshtha et al., 2014; Kryczyk et al., 2017). 
Pharmaceuticals have an important role in the treatment and prevention of disease in humans and animals. Unfortunately, they can also have unintended effects on living organisms in the environment. If possible, side effects on human and animal health are usually investigated, the study of potential environmental impact has only recently become a subject of interest for researchers. However, metabolism products or the combination of various biologically active compounds may have unpredictable effects.

The main source of contamination of water or soil with medicines are excrements. After being transported to municipal sewage systems, they reach the environment. Active substances may appear unchanged or in the form of metabolites. Wastewater treatment plants essentially remove solids and organic substances, while recalcitrant pollutants are often neglected.

Studies conducted all over the world indicate that NSAIDs are present in seawater, surface water and sewage (Lolic et al., 2015; Mainero Rocca et al., 2015). The presence of such drugs, even at low concentrations, can have a significant impact on water and land systems (Bácsi et al., 2016).

Piroxicam is a non-steroidal anti-inflammatory agent, widely used for chronic inflammatory conditions, particularly in treatment of rheumatoid arthritis, osteoarthritis, ankylosing spondylitis, pain in musculoskeletal disorders, acute gout and postoperative and postpartum pain. It characterized by low solubility and high permeability, therefore, adverse effects were reported when large doses are taken over a long period of time (Saganuwan and Orinya, 2016).

Piroxicam is a drug which mechanism of action is non-selective inhibition of cyclooxygenases. The ease with which a piroxicam molecule can transform from one prototropic form to another, depending on the environment conditions. This can be associated with the presence of hydrophobic chains with different lengths and surface charges in the environment which affects the interaction of piroxicam with micelles. Some studies show the impact of these factors on determining this balance (Chakraborty and Sarkar, 2005).

In the available literature there are works on the stability of piroxicam under different reaction environment conditions (Lemp et al., 2001; Puthli and Vavia, 2009; Starek et al., 2009; Aminuddin et al., 2011; Modhave et al., 2011). They indicate significant degradation of the molecule under hydrolytic, oxidative and photo-neutral conditions, and at the same time stability in dry heat and exposure to light in the solid state. The advanced degradation of piroxicam by oxidation (ozone or $\mathrm{H}_{2} \mathrm{O}_{2} / \mathrm{O}_{3}$ treatment) has been rarely explored (Feng et al., 2015). Lianou et al. (2018) presented a sonochemical oxidation of piroxicam with proposition of a degradation pathways. Authors point to ultrasonic irradiation as a promising technology with relatively high efficiency, but the scale of the process should still be analyzed in order to be able to be used commercially.

Some studies of the level of pharmaceuticals in wastewater from treatment, including many NSAIDs such as ibuprofen and naproxen, may lead to the finding of their toxic concentration in relation to fishes (Qun et al., 2008).
Prolonged exposure of fish to environmentally harmful concentrations of drugs may bioaccumulate and deteriorate their health (Schwaiger et al., 2004). It shows how important research is on the possibilities of eliminating pollutants from the environment. In some cases, it turned out that metabolites are more toxic than the original compound, which is an additional problem in remediation (van Leeuwen et al., 2011).

The natural ability of mushroom to neutralize toxic substances from their environment encouraged scientists to evaluate their use in biodegradation of xenobiotics in in vitro conditions. Biodegradation ability is connected with synthesis of non-selective enzymes in hyphae, especially the ones which can be excreted extracellularly and high efficiency in environmental cleansing processes is also caused by rapid growth, production of large amounts of biomass and widespread occurrence of hyphae in the environment (Ashoka et al., 2002; Ma and Zhai, 2014). The processes of mycoremediation use different mechanisms than those found in bacteria. The main advantage is that they do not require initial preparation for specific contamination (Asamudo et al., 2005). Lang describes that white rot fungi (WRF) show remarkable abilities to transform resistant impurities such as polycyclic aromatic hydrocarbons to non-toxic products (Lang et al., 1995). The main mechanism of degradation catalyzed by white rot fungi concerns the degradation of lignin in the natural environment. Extracellular lignin modifying enzymes (LMEs) have low substrate specificity, so they are capable of mineralizing a large number of various highly resistant organic impurities structurally related to lignin (Novotný et al., 2004; Kaneda et al., 2008; Wong, 2009).

Thanks to this ability, it is possible to use mushroom cultures to remove organic pollutants from the environment. For this reason, the edible mushroom $L$. edodes belonging to the WRF species was selected in this study. L. edodes is intensively studied due to the presence of compounds with therapeutic effects such as anti-cancer, hypocholesterolemic, hypotensive, hypoglycemic, antioxidant antifungal and antibacterial in fruiting bodies (Casaril et al., 2011; Mleczek et al., 2017; Muszyńska et al., 2017). Some of these compounds are well characterized and used, e.g., lentinan, lentinacin, eritadenin. The most studied active substance isolated from $L$. edodes is pure $\beta$ - $(1,3)$-D-glucan known as lentinan. As a result of in vitro and in vivo studies, the extracts of $L$. edodes and lentinan have been shown to have antitumor activity and for this reason preparations that contain them are used in conventional oncological therapy (Fulushima et al., 2001).

Due to the fact that mycelium $L$. edodes produces enzymes with oxidizing properties that can degrade xenobiotics, the aim of the work was to use this edible species for the human body and the environment to remedy them from the commonly used non-steroidal anti-inflammatory drug piroxicam. For this purpose, the in vitro culture of $L$. edodes was derived, followed by shaking mycelial cultures of this species to which piroxicam was added. The piroxicam biodegradation pathway was analyzed by UPLC/MS/MS. 


\section{MATERIALS AND METHODS}

\section{Reagents}

The chemicals: glucose, maltose extract, casein hydrolyzate, L-asparagine, adenine, $\mathrm{B}_{1}$ and $\mathrm{B}_{6}$ vitamins, agar, yeast extract were purchased from Sigma-Aldrich (St. Louis, $\mathrm{MO}$, United States). $\mathrm{NH}_{4} \mathrm{Cl}, \mathrm{KH}_{2} \mathrm{PO}_{4}, \mathrm{MgSO}_{4} \cdot 7 \mathrm{H}_{2} \mathrm{O}, \mathrm{CaCl}_{2} \cdot 6 \mathrm{H}_{2} \mathrm{O}$, $\mathrm{FeCl}_{3}, \quad \mathrm{MnSO}_{4} \cdot \mathrm{H}_{2} \mathrm{O}, \quad \mathrm{ZnSO}_{4} \cdot 7 \mathrm{H}_{2} \mathrm{O}$ were bought from PPHGolpharm (Kraków, Poland). HPLC grade methanol and dichloromethane came from Merck (Darmstadt, Germany). Water (quadruple-distilled) with a conductivity of less than $1 \mu \mathrm{S} \mathrm{cm}^{-1}$ was obtained using an S2-97A2 distillation apparatus (ChemLand, Stargard Szczeciński, Poland). Reference substance of piroxicam was from FIS (Vicenza, Italy).

\section{Mushroom Material}

The fruiting bodies of L. edodes (Berk.) Pegler of commercial origin, purchased at a supermarket in Poland. Taxonomic identification was based on the MycoKey $4.1^{1}$ by Muszyńska. Representative samples of the material are kept at the Department of Pharmaceutical Botany UJ CM (Kraków, Poland). Some of the young sporocarps of $L$. edodes were used to develop in vitro culture. Fragments of the hymenial part of sporocarps with an area of approx. $2 \mathrm{~mm}^{2}$ were used. The explants were degreased with $70 \%$ alcohol. After several rinsing with sterile redistilled water, the sporocarps fragments were transferred to the BD Sabouraud Agar with chloramphenicol (laminar airflow) medium. The solid cultures were incubated in a thermostat (ST500/B/40 Pol-Eko-Apparatus) at $23^{\circ} \mathrm{C}$ for 2 weeks (Picture 1). Microscopic analysis of obtained mycelium

${ }^{1}$ http://www.mycokey.com

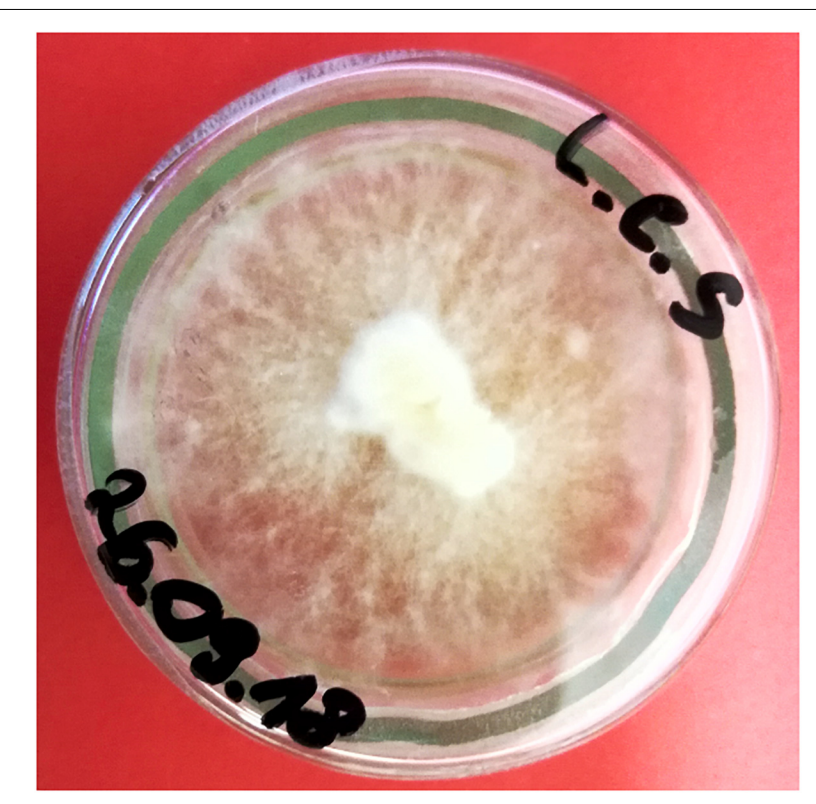

PICTURE 1 | Lentinula edodes in vitro culture on solid medium (picture made by Bożena Muszyńska). of $L$. edodes was carried out by Muszyńska. It showed a homogeneous nature of hyphae, free from contamination with other strains of fungi or bacteria. In the microscopic image, numerous branches and transverse walls were visible as well as the dikaryotic phase. Representative petri plates with mushroom material named LES/KB2 are kept at the Department of Pharmaceutical Botany UJ CM (Kraków, Poland).

Cultures from the solid medium were used to establish experimental cultures cultivated on the modified liquid Oddoux medium (Oddoux, 1957). The initial inoculum from the solid medium was $0.1 \mathrm{~g}$. The cultures were shaken at a rate of $140 \mathrm{rpm}$ (ALTEL, Poland) and incubated at a temperature of $23 \pm 2{ }^{\circ} \mathrm{C}$ under a photoperiod (10-h light, $900 \mathrm{~lx}$, and 14-h dark). The agitated liquid cultures of L. edodes were maintained for 2 weeks, and then subcultured.

\section{Experimental in vitro Culture}

Mycelium of $L$. edodes was passaged to Erlenmayer flasks containing $250 \mathrm{~mL}$ of liquid Oddoux medium with addition of piroxicam in daily dosages used by human (10, 20, and $80 \mathrm{mg}$ ). The flasks were put into rotary shaker (ALTEL, Poland) with 140 $\mathrm{RPM}$ for 2 weeks in $23 \pm 2{ }^{\circ} \mathrm{C}$ under a photoperiod (10-h light, $900 \mathrm{~lx}$, and 14-h dark). After 14 days of incubation, biomass was separated from the medium, rinsed with redistilled water and prepared for lyophilization as well as separated liquid medium. Then, the obtained mycelium from in vitro cultures and culture media were subjected to the lyophilization process (Freezone 4.5, Labconco) (Picture 2).

\section{Sample Preparation}

The powdered in a mortar mushroom materials (mycelium from in vitro cultures on media containing piroxicam and culture

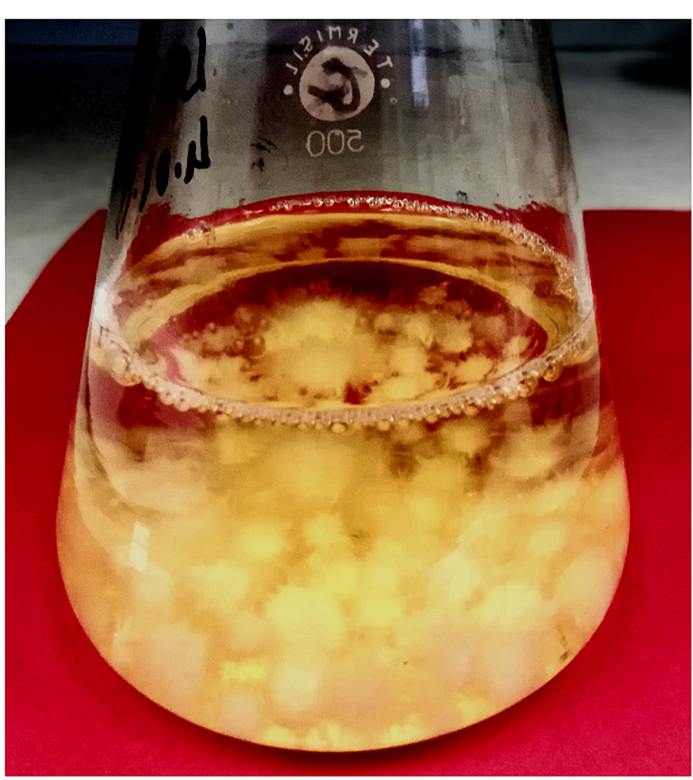

PICTURE 2 | Experimental in vitro culture of $L$. edodes with addition of piroxicam in liquid Oddoux medium (picture made by Bożena Muszyńska). 
media) at $5 \mathrm{~g}$ were extracted with a mixture of methanol and dichloromethane in ratio: 75:25 $(v / v)$ in an ultrasonic bath at $49 \mathrm{kHz}$ for $30 \mathrm{~min}$ (Sonic-2, Polsonic). Merged extracts $(300 \mathrm{~mL})$ were concentrated to dryness using a rotary vacuum evaporator at $22 \pm 2^{\circ} \mathrm{C}$, and were subjected to UPLC/MS/MS analysis.

\section{UPLC/MS/MS Analysis}

The UPLC-MS/MS system consisted of a Waters ACQUITY ${ }^{\circledR}$ UPLC $^{\circledR}$ (Waters Corp., Milford, CT, United States) coupled to a Waters TQD mass spectrometer (electrospray ionization mode ESI-tandem quadrupole). Chromatographic separations were carried out using the Acquity UPLC BEH $\mathrm{C}_{18}$ column $(2.1 \times 100 \mathrm{~mm}, 1.7 \mu \mathrm{m}$ particle size $)$, equipped with Acquity UPLC BEH C 18 VanGuard pre-column $(2.1 \times 5 \mathrm{~mm}, 1.7 \mu \mathrm{m}$ particle size). The column was maintained at $40^{\circ} \mathrm{C}$, and eluted under gradient conditions using from 95 to $0 \%$ of eluent A over

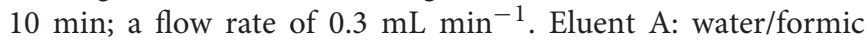
acid $(0.1 \%, v / v)$; eluent B: acetonitrile/formic acid $(0.1 \%, v / v)$. Chromatograms were recorded using Waters e $\lambda$ PDA detector. Spectra were analyzed in 200-700 nm range with $1.2 \mathrm{~nm}$ resolution and sampling rate 20 points $\mathrm{s}^{-1}$. MS detection settings of Waters TQD mass spectrometer were: source temperature $150^{\circ} \mathrm{C}$, desolvation temperature $350^{\circ} \mathrm{C}$, desolvation gas flow rate $600 \mathrm{~L} \mathrm{~h}^{-1}$, cone gas flow $100 \mathrm{~L} \mathrm{~h}^{-1}$, capillary potential $3.00 \mathrm{kV}$, cone potential $30 \mathrm{~V}$. Nitrogen was used for both nebulizing and drying gas. The data were obtained in a scan mode ranging from 50 to $1000 \mathrm{~m} / z$ in time 0.5 s intervals; 8 scans were summed up to get the final spectrum. Collision activated dissociations analyses were carried out with the energy of $40 \mathrm{eV}$. Consequently, the ion spectra were obtained by scanning from 50 to $500 \mathrm{~m} / z$ range. Data acquisition software was MassLynx V 4.1 (Waters).

\section{RESULTS AND DISCUSSION}

A variety of methods were used to remove drug contaminants from wastewater and drinking water treatment, such as sonochemical degradation of ibuprofen (Xiao et al., 2014), naproxen (Im et al., 2013), diclofenac (Naddeo et al., 2013). Other ways to removing possible pollutants are phytoremediation or mycoremediation (Nowrotek et al., 2016; Topal et al., 2016; Rodríguez-Espinosa et al., 2018).

Researches about usage of WRF for wastewater treatment have been conducting for many years (Pointing, 2001; Lamrood and Ralegankar, 2013). The ability of the WRF to degrade various pharmaceutical compounds, which can be transmitted to the environment and thus be potentially harmful, has also been reported (Tsujiyama et al., 2013; Riggins and Gregory, 2015; Eldridge et al., 2017; Muszyńska et al., 2018b).

Based on research data there are some works about using fungi in the process of decomposition of polycyclic NSAIDs (Suryanarayanan et al., 2012; Domaradzka et al., 2015). Complete degradation was described only for olsazine (Razo-Flores et al., 1997). The first step of the transformation is most often hydroxylation catalyzed by cytochrom P-450 monooxygenases, or oxygenation by laccases and three peroxidases: lignin peroxidase, manganese-dependent peroxidase and versatile peroxidase manganese-dependent peroxidase. Applied species were able to dechlorinate halogenated aromatics (MarcoUrrea et al., 2009). Gonda et al. (2016) presented the first

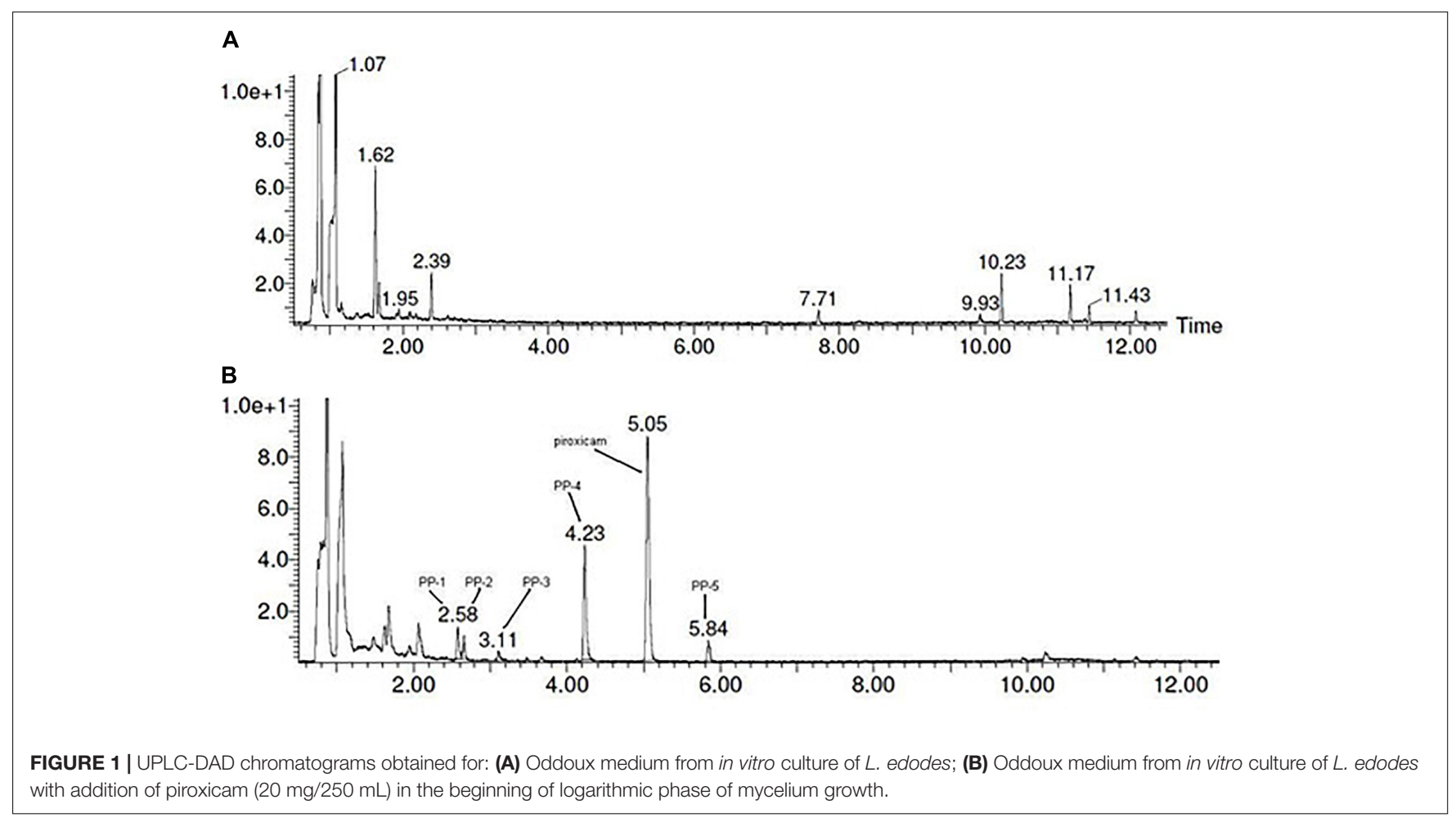


research about fungal transformation of piroxicam and diflunisal. These authors discussed the ability of the species used to biotransformation of chosen medicines, and the possibility of using high concentrations of these substances and their chemical similarity. Compounds produced by fungi (e.g., Aspergillus nidulans, Bipolaris tetramera) were similar to metabolites, which can be less or more toxic compared to the original substances. During oxidation the polarity of compounds increases, which may affect their less bioaccumulation. However, it may happen that thanks to fungal enzymes, this process can be increased. From the investigated drugs, piroxicam was the most resistant to used strains (Gonda et al., 2016).

TABLE 1 | Proposed structures and fragmentation pattern of piroxicam by mycelium from in vitro cultures of Lentinula edodes.

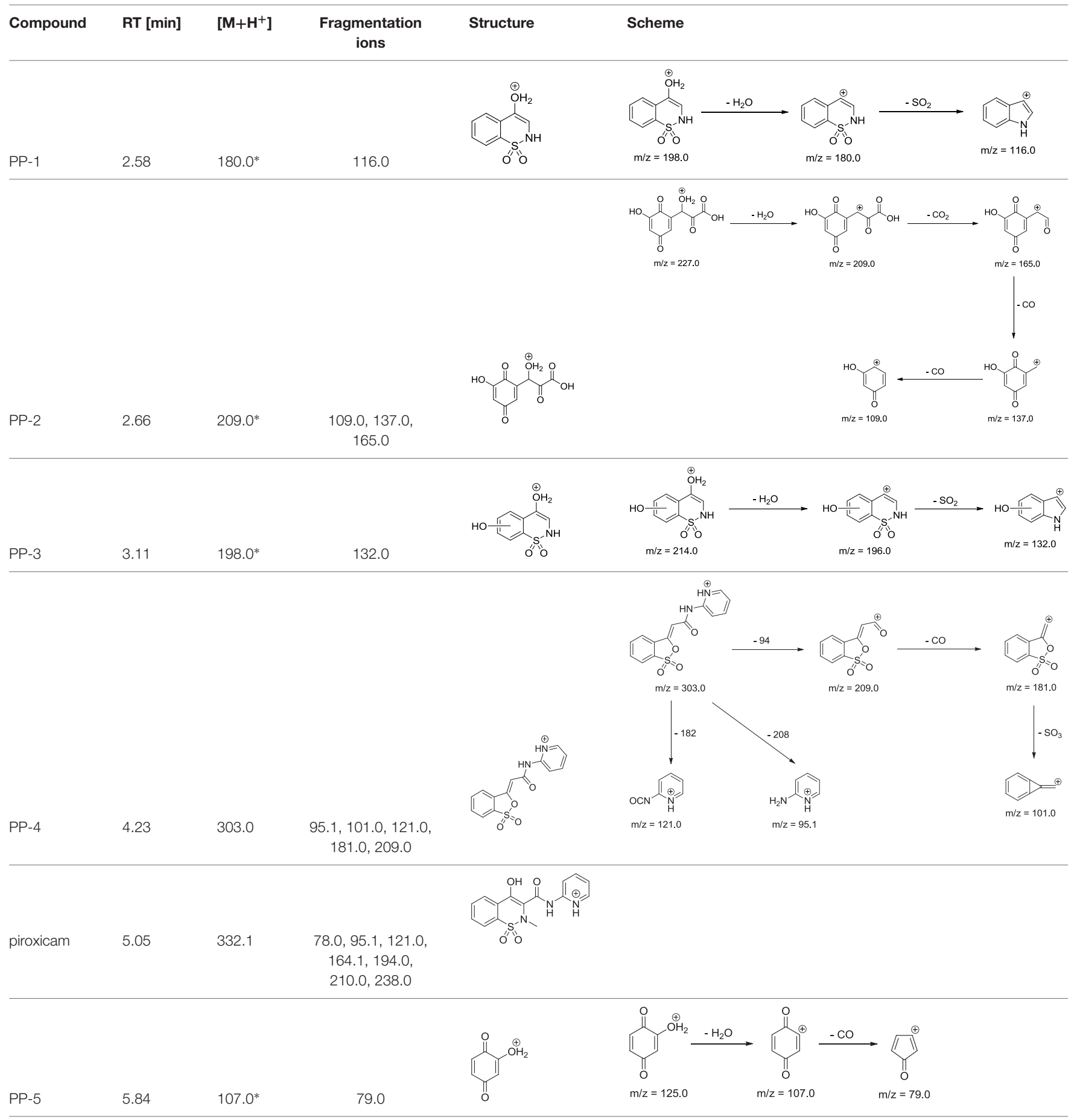

* $\left[\mathrm{M}-\mathrm{H}_{2} \mathrm{O}\right]^{+}$ 
Jimenez et al. (2018) described biological, photochemical and thermal degradation of three oxicams in samples river water. Obtained results indicated that the direct sunlight irradiation promoted a fast degradation of drugs, while the chemical reactions in solution were less important. After about month several degradation products were found. Authors proposed their structures and pathways of degradation, created by photochemical reactions as the main reason of the degradation of the oxicams in water, except hydrolysis.

Continuing the implementation of the subject our team (Dąbrowska et al., 2018) made research project about the ability of L. edodes's mycelium from in vitro cultures to degrade antibiotics. Authors showed that the examined mycelia take short time duration to remove the cefuroxime axetil from the medium. An observed mycoremediation process can be used as an alternative to other methods for remediation cephalosporins contamination.

In presented experiment good biomass growth for $L$. edodes could be obtained from agitating liquid cultures on the modified Oddoux medium and on the same medium with addition of piroxicam. The dynamics of mycelium growth in liquid Oddoux medium did not differ from that registered in earlier researches, and with addition of piroxicam was in the same level (Muszyńska et al., 2015, 2018a). The addition of piroxicam to medium lead to increase of $L$. edodes biomass in their culture in vitro (average to $1.2 \mathrm{~g}$ dry weight per $1 \mathrm{~L}$ of mushroom medium). However, growth stimulation was not dependent on applied dose of piroxicam.

Analysis of the extracts of the medium and mushroom mycelium with no addition of piroxicam showed no peaks on UV chromatogram thus all the compounds observed on the chromatograms of the extracts of the mushroom materials with added drug were most probably products of its biodegradation (Figure 1).

The identification of the degradation products of piroxicam was performed on a basis of UPLC/MS analysis and supported with fragmentation patterns obtained from MS/MS experiments. The proposed structures of the degradation products are shown in Table 1. The proposed fragmentation patterns of piroxicam and its degradation products are shown on Figure 2.

The degradation process was found to affect primarily the linker between the thiazine and the piperidine ring, leading to its oxidation and cleavage. Additionally, oxidation of the benzothiazine moiety was observed, leading to hydroxylation and oxidation of the phenyl ring (PP-2, PP-3, and PP-5), as well as oxidation of the thiazine ring leading to partial (PP-4) or complete removal (PP-2 and PP-5) of the sulfonamide moiety (Table 1). The molecular ion $\left(\left[\mathrm{M}+\mathrm{H}^{+}\right]\right)$peak of $\mathrm{m} / \mathrm{z} 332.1$ fragmented into 7 ions of $\mathrm{m} / z$ 78.0, 95.1, 121.0, $164.1,194.0,210.0,238.0$. Based on the fragmentation ions for obtained degradation products (PP-1 to PP-5) and the available literature data, we have attempted to identify possible ways of degradation of piroxicam in fungal environment. It seems that the degradation process led finally to 2-hydroxybenozquinone, which may be further oxidized yielding inorganic compounds. What more piroxicam biodegradation was on the same level for used different concentration of piroxicam $(10 ; 20 ; 80 \mathrm{mg}$ per $250 \mathrm{~mL}$ of medium), what may suggest, that the ability of the mushroom to degrade the drug was not exceeded even in the highest concentration of piroxicam.

The presence of electron withdrawing functional groups, such as amide, carboxylic, halogen, and nitro group generates an electron deficiency and thus renders the compounds less

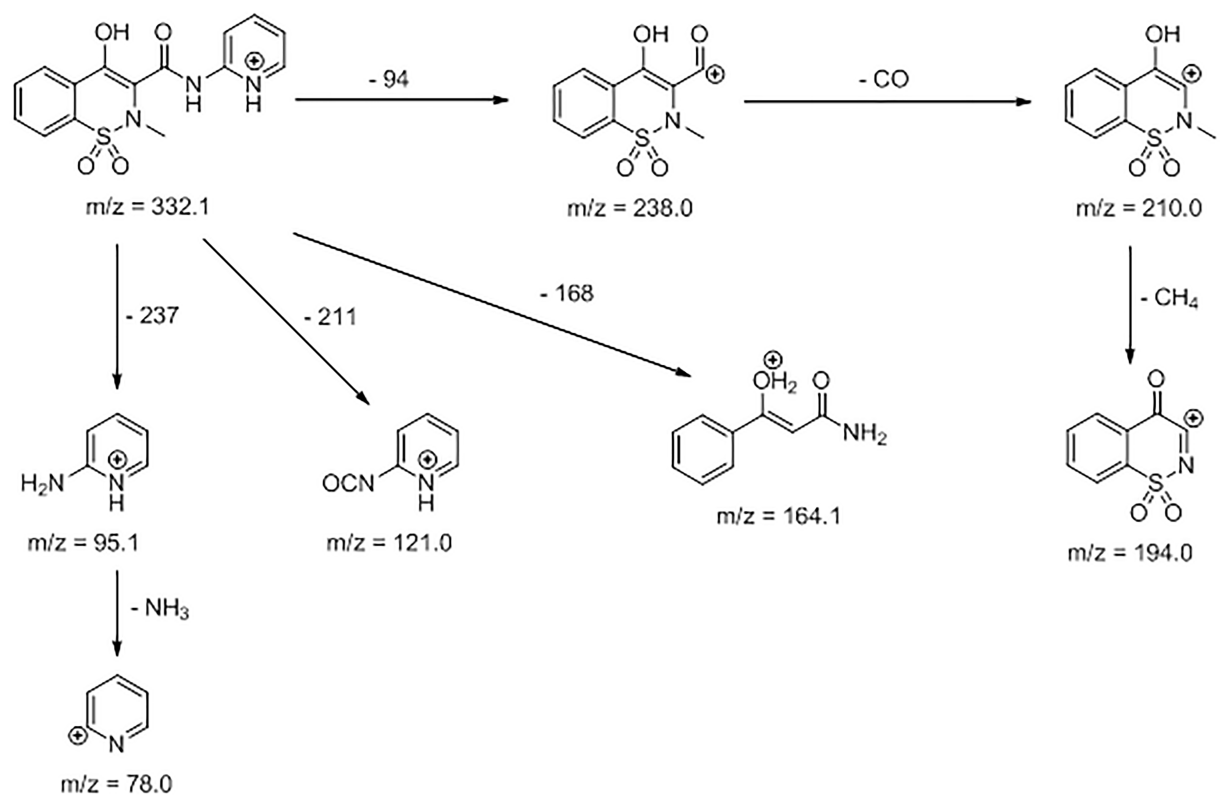

FIGURE 2 | Proposed fragmentation pattern of piroxicam by mycelium from in vitro cultures of $L$. edodes. 
susceptible to oxidative catabolism. Whereas while electron-donating functional groups, such as amine, hydroxyl, alkoxy, make the molecules more susceptible to electrophilic attack by oxygenases (Yang et al., 2013). In this review authors reported many cases of bioremediation for drugs form various classes, quoting source works. To our best knowledge such studies for piroxicam have not been carried out yet. A specific class of enzymes, commonly secreted by WRF, called LMEs, is of particular interest for biodegradation of pharmaceuticals. The most studied LMEs are glycosylated heme-containing peroxidases, lignin and manganese peroxidases, and a copper-containing phenoloxidase and laccase (Pointing, 2001; Janusz et al., 2017). LMEs are primarily oxidoreductases that catalyze the flow of electrons from one substrate to another, and work by generating free radicals that randomly react with the lignin polymer, breaking covalent bonds and releasing phenolic compounds. Thanks to such mechanism, advanced oxidation reactions take place. The lignin degrading-system is extracellular, non-stereoselective and non-specific, able to cleave the carbon-carbon and carbon-oxygen bonds, regardless of the conformation of the chiral carbon of lignin (Fernando and Aust, 1994). This feature is partly due to highly reactive free radical degradation mechanisms that are ideal for the biodegradation of organic pollutants in the environment. Gonda et al. (2016) described a degradation pathway of piroxicam based on fragmentation pattern developed by other authors. Presented fragmentation showed, that the pyridine ring was hydroxylated, and a new compound was identified as hydroxypiroxicam.

The results obtained in presented research, are in accordance with this observation, since pyridine and thiazine moieties, which are electron rich regions of the piroxicam molecule, were readily degraded. At the same time phenyl ring was found to be quite stable and underwent only partial degradation via oxidation to 2-hydroxyquinone.

Results received under described work indicate on a high level of the degradation degree of examined drug by analyzed mycelia.

\section{REFERENCES}

Aminuddin, M., Nazim, U., and Ahmad, I. (2011). Photo- and thermal degradation of piroxicam in aqueous solution. Indian J. Pharm. Sci. 73, 387-391. doi: 10. 4103/0250-474X.95615

Asamudo, N. U., Dada, A. S., and Ezeronye, O. U. (2005). Biorememediation of textile effluent using Phanerochaete chrysosporium. Afr. J. Biotechnol. 13, 1548-1553.

Ashoka, G., Geetha, M. S., and Sullia, S. B. (2002). Bioleaching of composite textile dye effluent using bacterial consortia. Asian J. Microb. Biotechnol. Environ. Sci. 4, 65-68.

Bácsi, I., B-Béres, V., Kókai, Z., Gonda, S., Novák, Z., Nagy, S. A., et al. (2016). Effects of non-steroidal anti-inflammatory drugs on cyanobacteria and algae in laboratory strains and in natural algal assemblages. Environ. Pollut. 212, 508-518. doi: 10.1016/j.envpol.2016. 02.031

Casaril, K. B. P. B., Kasuya, M. C. M., and Vanetti, M. C. D. (2011). Antimicrobial activity and mineral composition of Shiitake mushrooms cultivated on agricultural waste. Braz. Arch. Biol. Technol. 54, 991-1002. doi: 10.1590/S151689132011000500017
These information shows necessity for further studies, which are still indispensable in order to have a comprehensive knowledge of ability of WRF to remediate pharmaceuticals.

\section{CONCLUSION}

Pharmaceuticals in the environment can potentially cause to the formation of resistant strains of bacteria as well as recalcitrant toxins. Presented pilot tests showed that the examined mycelium from in vitro cultures of $L$. edodes mushroom take short time duration to remove the piroxicam from the medium, and thus mycoremediation can be used as an alternative to other methods for remediating contamination of this compound. Thanks to reproducible culture conditions, mycelium from in vitro cultures used in the experiment allow the monitoring of the accumulation and biodegradation of piroxicam from the media and the determination of the degree of bioaccumulation, and this further allows the selection of species for environmental remediation from this compound which are detrimental to living organisms. The results confirm the possibility of the use of the investigated mycelia of $L$. edodes from in vitro cultures, in remediation of piroxicam.

\section{AUTHOR CONTRIBUTIONS}

$\mathrm{BM}$ and WO conceived and designed the study. BM performed the experimental section. MD and MS cooperated in conducting the experiments, and wrote and revised the manuscript. JL and JP-P performed the linguistic correction. PZ performed the UPLC/MS/MS analysis.

\section{FUNDING}

This study was supported by the Jagiellonian University Project No. K/ZDS/007860.

Chakraborty, H., and Sarkar, M. (2005). Interaction of piroxicam with micelles: effect of hydrophobic chain length on structural switchover. Biophys. Chem. 117, 79-88. doi: 10.1016/j.bpc.2005.04.016

Dąbrowska, M., Muszyńska, B., Starek, M., Żmudzki, P., and Opoka, W. (2018). Degradation pathway of cephalosporin antibiotics by in vitro cultures of Lentinula edodes and Imleria badia. Int. Biodeter. Biodegr. 127, 104-112. doi: 10.1016/j.ibiod.2017.11.014

Das, N. (2005). Heavy metals biosorption by mushrooms. Nat. Prod. Rad. 4, 454-459.

Domaradzka, D., Guzik, U., and Wojcieszyńska, D. (2015). Biodegradation and biotransformation of polycyclic non-steroidal anti-inflammatory drugs. Rev. Environ. Sci. Bio. 14, 229-239. doi: 10.1007/s11157-015-9364-8

Eldridge, H. C., Milliken, A., Farmer, C., Hampton, A., Wendland, N., Coward, L., et al. (2017). Efficient remediation of $17 \alpha$-ethinylestradiol by Lentinula edodes (shiitake) laccase. Biocatal. Agric. Biotechnol. 10, 64-68. doi: 10.1016/j.bcab. 2017.02.004

Feng, L., Watts, M. J., Yeh, D., Esposito, G., and van Hullebusch, E. D. (2015). The efficacy of ozone/BAC treatment on non-steroidal anti-inflammatory drug removal fromdrinking water and surface water. Ozone Sci. Eng. 37, 343-356. doi: 10.1080/01919512.2014.999910 
Fernando, T., and Aust, S. D. (1994). "Biodegradation of toxic chemicals by white rot fungi," in Biological Degradation and Bioremediation of Toxic Chemicals, ed. G. R. Chaudhry (Portland, OR: Dioscorides Press), 386-402.

Fulushima, M., Ohashi, T., Fuliwara, Y., Sonoyama, K., and Nakano, M. (2001). Cholesterol-lowering effects of Maitake fiber, Shiitake fiber and Enokitake fiber in rats. Exp. Biol. Med. 226, 758-765. doi: 10.1177/153537020222600808

Gonda, S., Kiss-Szikszai, A., Szûcs, Z., Balla, B., and Vasas, G. (2016). Efficient biotransformation of non-steroid anti-inflammatory drugs by endophytic and epiphytic fungi from dried leaves of a medicinal plant, Plantago lanceolata L. Int. Biodeterior. Biodegradation 108, 115-121. doi: 10.1016/j.ibiod.2015.12.018

Im, J.-K., Heo, J., Boateng, L. K., Her, N., Flora, J. R. V., Yoon, J., et al. (2013). Ultrasonic degradation of acetaminophen and naproxen in the presence of single-walled carbon nanotubes. J. Hazard. Mater. 254, 284-292. doi: 10.1016/j. jhazmat.2013.04.001

Janusz, G., Pawlik, A., Sulej, J., Świderska-Burek, U., Jarosz-Wilkołazka, A., and Paszczyński, A. (2017). Lignin degradation: microorganisms, enzymes involved, genomes analysis and evolution. FEMS Microbiol. Rev. 41, 941-962. doi: 10. 1093/femsre/fux049

Jimenez, J. J., Munoz, B. E., Sanchez, M. I., and Pardo, R. (2018). Forced and longterm degradation assays of tenoxicam, piroxicam and meloxicam in river water. Degradation products and adsorption to sediment. Chemosphere 191, 903-910. doi: 10.1016/j.chemosphere.2017.10.056

Kaneda, M., Rensing, K. H., Wong, J. C. T., Banno, B., Mansfield, S. D., and Samuels, A. L. (2008). Tracking monolignols during wood development in lodgepole pine. Plant Physiol. 147, 1750-1760. doi: 10.1104/pp.108.121533

Kryczyk, A., Piotrowska, J., Sito, M., Sułkowska-Ziaja, K., Dobosz, K., Opoka, W., et al. (2017). Remediation capacity of $\mathrm{Cd}$ and $\mathrm{Pb}$ ions by mycelia of Imleria badia, Laetiporus sulphureus and Agaricus bisporus in vitro culture. J. Environ. Sci. Health B 52, 617-622. doi: 10.1080/03601234.2017.1330068

Kulshreshtha, S., Mathur, N., and Bhatnagar, P. (2014). Mushroom as a product and their role in mycoremediation. $A M B$ Express 4:29. doi: 10.1186/s13568014-0029-8

Lamrood, P. Y., and Ralegankar, S. D. (2013). Biosorption of Cu, Zn, Fe, Cd, Pb and Ni by non-treated biomass of some edible mushrooms. Asian J. Exp. Biol. Sci. 4, 190-195.

Lang, E., Eller, I., Kleeberg, R., Martens, R., and Zadrazil, F. (1995). “Interaction of white rot fungi and microorganisms leading to biodegradation of soil pollutants," in Proceedings of the 5th International FZK/ TNo Conference on Contaminated Soil. 30th Oct-5Nov, Maustrient, Amsterdam. doi: 10.1007/97894-011-0421-0_111

Lemp, E., Zanocco, A. L., and Gunther, G. (2001). Sentilized photoxygenation of piroxicam in neat solvents and solvent mixtures. J. Photochem. Photobiol. B 31, 165-170. doi: 10.1016/S1011-1344(01)00265-2

Lianou, A., Frontistis, Z., Chatzisymeon, E., Antonopoulou, M., Konstantinou, I., and Mantzavinos, D. (2018). Sonochemical oxidation of piroxicam drug: effect of key operating parameters and degradation pathways. J. Chem. Technol. Biotechnol. 93, 28-34. doi: 10.1002/jctb.5346

Lolic, A., Paíga, P., Santos, L. H. M. L. M., Ramos, S., and Correia Mand Delerue-Matos, C. (2015). Assessment of non-steroidal anti-inflammatory and analgesic pharmaceuticals in seawaters of North of Portugal: occurrence and environmental risk. Sci. Total Environ. 508, 240-250. doi: 10.1016/j.scitotenv. 2014.11.097

Ma, J., and Zhai, G. (2014). Antibiotic contamination: a global environment issue. J. Bioremed. Biodeg. 5, 5-6. doi: 10.3390/ijerph15091942

Mainero Rocca, L., Gentili, A., Caretti, F., Curini, R., and Pérez-Fernández, V. (2015). Occurrence of non-steroidal anti-inflammatory drugs in surface waters of central Italy by liquid chromatography-tandem mass spectrometry. Int. J. Environ. Anal. Chem. 95, 685-697. doi: 10.1080/03067319.2015.1046059

Marco-Urrea, E., Perez-Trujillo, M., Vicent, T., and Caminal, G. (2009). Ability of white-rot fungi to remove selected pharmaceuticals and identification of degradation products of ibuprofen by Trametes versicolor. Chemosphere 74, 765-772. doi: 10.1016/j.chemosphere.2008.10.040

Mleczek, M., Siwulski, M., Rzymski, P., Niedzielski, P., Gąsecka, M., Jasinska, A., et al. (2017). Multi-elemental analysis of Lentinula edodes mushrooms available in trade. J. Environ. Sci. Health Part B 52, 196-205. doi: 10.1080/03601234.2017. 1261551

Modhave, D. T., Handa, T., Shah, R. P., and Singh, S. (2011). Successful characterization of degradation products of drugs using LC-MS tools: application to piroxicam and meloxicam. Anal. Methods 3, 2864-2872. doi: 10.1039/clay05493g

Muszyńska, B., Grzywacz, A., Kała, K., and Gdula-Argasińska, J. (2018a). The antiinflammatory potential of in vitro cultures of white button mushroom, Agaricus bisporus (Agaricomycetes) in CaCo-2 cells. Int. J. Med. Mushrooms 20, 129-139. doi: 10.1615/IntJMedMushrooms.2018025408

Muszyńska, B., Żmudzki, P., Lazur, J., Kała, K., Sułkowska-Ziaja, K., and Opoka, W. (2018b). Analysis of the biodegradation of synthetic testosterone and $17 \alpha$-ethynylestradiol using the edible mushroom Lentinula edodes. 3 Biotech. 8:424. doi: 10.1007/s13205-018-1458-x

Muszyńska, B., Pazdur, P., Lazur, J., and Sułkowska-Ziaja, K. (2017). Lentinula edodes (Shiitake) - biological activity. Med. Int. Rev. 108, 189-195.

Muszyńska, B., Smalec, A., Sułkowska-Ziaja, K., Opoka, W., Reczyński, W., and Baś, B. (2015). Culinary-medicinal Agaricus bisporus (white button mushroom) and its in vitro cultures as a source of selected biologicallyactive elements. J. Food Sci. Technol. 52, 7337-7344. doi: 10.1007/s13197-0151830-3

Naddeo, V., Landi, M., Scannapieco, D., and Belgiorno, V. (2013). Sonochemical degradation of twenty-three emerging contaminants in urban wastewater. Desal. Water Treat. 51, 6601-6608. doi: 10.1080/19443994.2013.769696

Novotný, C., Svobodová, K., Erbanová, P., Cajthaml, T., Kasinath, A., Lang, E., et al. (2004). Ligninolytic fungi in bioremediation: extracellular enzyme production and degradation rate. Soil Biol. Biochem. 4, 1545-1551. doi: 10.1016/j.soilbio. 2004.07.019

Nowrotek, M., Sochacki, A., Felis, E., and Miksch, K. (2016). Removal of diclofenac and sulfamethoxazole from synthetic municipal waste water in microcosm downflow constructed wetlands: start-up results. Int. J. Phytorem. 18, 157-163. doi: 10.1080/15226514.2015.1073669

Oddoux, L. (ed.) (1957). Recherches sur les Mycéliumssecondaires des Homobasidiésen Culture Pure. Lyon: Imprimerie de Trevoux.

Pointing, S. (2001). Feasibility of bioremediation by white-rot fungi. Appl. Microbiol. Biotechnol. 57, 20-33. doi: 10.1007/s002530100745

Puthli, S., and Vavia, P. R. (2009). Stability studies of microparticulate system with piroxicam as model drug, AAPS Pharm. Sci. Tech. 10, 872-880. doi: 10.1208/ s12249-009-9280-8

Qun, B., Gagne, F., and Blaise, C. (2008). An investigation into the acute and chronic toxicity of eleven pharmaceuticals (and their solvents) found in wastewater effluent on the cnidarian. Hydra attenuata. Sci. Total Environ. 389, 306-314. doi: 10.1016/j.scitotenv.2007.08.038

Razo-Flores, E., Luijten, M., Donlon, B., Lettinga, G., and Field, J. A. (1997). Complete biodegradation of the azo dye azodisalicylate under anaerobic conditions. Environ. Sci. Technol. 31, 2098-2103. doi: 10.1021/es960 933o

Riggins, A., and Gregory, D. J. (2015). Degradation of 17 $\alpha$-Ethinylestradiol (EE2) Using Laccases Isolated from the White rot Fungi Lentinula edodes, Trametes versicolor, and Agaricus bisporus. Charlotte, NC: University of North Carolina at Charlotte.

Rodríguez-Espinosa, P. F., Mendoza-Pérez, J. A., Tabla-Hernandez, J., MartínezTavera, E., and Monroy-Mendieta, M. M. (2018). Biodegradation and kinetics oforganic compounds and heavy metals in an artificial wetland system (AWS) by using water hyacinths as a biological filter. Int. J. Phytoremediation 20, 35-43. doi: 10.1080/15226514.2017.1328397

Saganuwan, S. A., and Orinya, O. A. (2016). Toxico-neurological effects of piroxicam in monogastric animals. J. Exp. Neurosci. 10, 121-128. doi: 10.4137/ JEN.S40144

Schwaiger, J., Ferling, H., Mallow, U., Wintermayr, H., and Negele, R. D. (2004). Toxic effects of the nonsteroidal anti-inflammatory drug diclofenac: Part I: histopathological alterations and bioaccumulation in rainbow trout. Aquat. Toxicol. 68, 141-150. doi: 10.1016/j.aquatox.2004. 03.014

Starek, M., Krzek, J., Tarsa, M., and Żylewski, M. (2009). Determination of piroxicam and degradation products in drugs by TLC. Chromatographia 69 , 351-356. doi: 10.1365/s10337-008-0883-0

Suryanarayanan, T. S., Thirunavukkarasu, N., Govindarajulu, M. B., and Gopalan, V. (2012). Fungal endophytes: an untapped source of biocatalysts. Fungal Divers. 54, 19-30. doi: 10.1007/s13225-012-0168-7

Topal, M., Şenel, G. U., Öbek, E., and Topal, E. I. A. (2016). Bioaccumulation of tetracycline and degradation products in Lemna gibba L. exposed to secondary 
effluents. Desalin. Water Treat. 57, 8270-8277. doi: 10.1080/19443994.2015. 1018332

Tsujiyama, S., Muraoka, T., and Takada, N. (2013). Biodegradation of 2,4dichlorophenol by shiitake mushroom (Lentinula edodes) using vanillin as an activator. Biotechnol. Lett. 4, 1079-1083. doi: 10.1007/s10529-013$1179-5$

van Leeuwen, J. S., Vredenburg, G., Dragovic, S., Tjong, T. F. J., Vos, J. C., and Vermeulen, N. P. E. (2011). Metabolism related toxicity of diclofenac in yeast as model system. Toxicol. Lett. 200, 162-168. doi: 10.1016/j.toxlet.2010. 11.010

Wong, D. W. S. (2009). Structure and action mechanism of ligninolytic enzymes. Biotechnol. Appl. Biochem. 157, 174-209. doi: 10.1007/s12010-008$8279-\mathrm{z}$

Xiao, R., He, Z., Diaz-Rivera, D., Pee, G. Y., and Weavers, L. K. (2014). Sonochemical degradation of ciprofloxacin and ibuprofen in the presence of matrix organic compounds. Ultrason. Sonochem. 21, 428-435. doi: 10.1016/j. ultsonch.2013.06.012
Yang, S., Hai, F. I., Nghiem, L. D., Price, W. E., Roddick, F., Moreira, M. T., et al. (2013). Understanding the factors controlling the removal of trace organic contaminants by white-rot fungi and their lignin modifying enzymes: a critical review. Bioresour. Technol. 141, 97-108. doi: 10.1016/j.biortech.2013. 01.173

Conflict of Interest Statement: The authors declare that the research was conducted in the absence of any commercial or financial relationships that could be construed as a potential conflict of interest.

Copyright @ 2019 Muszyńska, Dabrowska, Starek, Żmudzki, Lazur, Pytko-Polończyk and Opoka. This is an open-access article distributed under the terms of the Creative Commons Attribution License (CC BY). The use, distribution or reproduction in other forums is permitted, provided the original author(s) and the copyright owner(s) are credited and that the original publication in this journal is cited, in accordance with accepted academic practice. No use, distribution or reproduction is permitted which does not comply with these terms. 